\title{
Streptococcus thermophilus
}

National Cancer Institute

\section{Source}

National Cancer Institute. Streptococcus thermophilus. NCI Thesaurus. Code C86808.

A species of facultatively anaerobic, Gram positive, cocci shaped bacteria in the phylum Firmicutes. This species is alpha hemolytic, catalase and arginine deaminase negative, does not grow in $6.5 \% \mathrm{NaCl}$ and does not hydrolyze esculin. It can ferment fructose, glucose, lactose, mannose and sucrose but not amygdalin, arabinose, cellobiose, inulin, maltose, mannitol, salicin, sorbitol, trehalose and xylose. S. thermophilus is found in milk and milk products, used to manufacture cheese and yogurt and is not known to be a human pathogen. 